\title{
Endonasal Dacryocystorhinostomy done with and without Silicon Tube Stents: A Comparative Case Series Analysis Study
}

\author{
Sudhir M Naik, Annapurna S Mushannavar, S Ravishankara, Mohan K Appaji, MK Goutham \\ Nonthombam Pinky Devi, Sarika S Naik
}

\begin{abstract}
Background/objectives: Neo-ostium cicatrization and closure is considered a major factor for surgical failure in endoscopic dacryocystorhinostomy (EnDCR). Wide neo-ostium, mucosal flaps, sac marsupialization with primary healing and silicone tube stent improves surgical outcomes of EnDCR.
\end{abstract}

Materials and methods: EnDCR were done in 238 patients. Group A included 172 patients where no stents were used and group B included 66 patients where silicon tube stents were used. All the surgeries were done under general anesthesia.

Results: In our study, 89.53\% success in syringing patency was seen in group A, $89.39 \%$ success in syringing patency was seen in group B at 6 months of follow-up. No significant difference in success rate were seen in the two study groups.

Conclusion: No significant difference in EnDCR success rates were seen with the use of stents in our study. So stenting probing and dilatation are not advocated routinely in all cases and a wide neo-ostium with mucosal flaps and primary healing is the secret to success.

Keywords: Endonasal dacryocystorhinostomy, Silicone tube stent, Nasolacrimal duct obstruction, Neo-ostium.

How to cite this article: Naik SM, Mushannavar AS, Ravishankara S, Appaji MK, Goutham MK, Devi NP, Naik SS. Endonasal Dacryocystorhinostomy done with and without Silicon Tube Stents: A Comparative Case Series Analysis Study. Int J Head Neck Surg 2012;3(3):147-153.

\section{Source of support: Nil}

Conflict of interest: None declared

\section{INTRODUCTION}

The success of endoscopic dacryocystorhinostomy (EnDCR) are revolutionized by the introduction of high resolution endoscopes. ${ }^{1}$ EnDCR over the past decade have replaced conventional external DCR in correcting primary and recurrent lacrimal obstruction., ${ }^{2,3}$

The advantages of EnDCR over external DCR are (a) improved visualization of lacrimal sac pathology, (b) treating coexisting sinonasal pathology simultaneously, ${ }^{2,3}$ (c) avoiding external skin incision, facial scar, injury to medial palpebral ligament, orbicularis oculi muscle, (d) reduction in operating time, bleeding and morbidity, ${ }^{2,3}$ (e) medial canthal anatomy is intact which reduces angular vein damage, ${ }^{2,3}$ (f) nasolacrimal duct (NLD) pumping action is spared which promotes faster healing, ${ }^{2,3}$ (g) can be performed easily under local anesthesia with equally better results. ${ }^{4,5}$
Inspite of several advantages of EnDCR, there are higher failure rate due to the obstruction of neo-ostium by granulation and synechia that forms postoperatively. ${ }^{6} \mathrm{Neo}-$ ostium closure was considered a major factor for surgical failure. ${ }^{1}$ In external DCR, several methods such as use of silicone stent, application of mitomycin- $\mathrm{C}$ to the neo-ostium and suturing of the mucosal flaps have been suggested for providing permanent neo-ostium opening after completion of mucosal healing. ${ }^{1}$

EnDCR enables the surgeon to identify and correct common intranasal causes of DCR failures such as adhesions, an enlarged middle turbinate, or an infected ethmoidal sinus. ${ }^{2,3}$ It has definitive role in failed external DCR cases and revision cases. ${ }^{2,3}$ In EnDCR, insertion of silicone stent is the most commonly preferred procedure as it improves surgical outcomes of EnDCR. ${ }^{1}$ Many surgeons advocate the use of silicone stent placed as a loop in the superior and inferior canaliculi, through the common canaliculus and lacrimal sac into nose. ${ }^{1}$

Success rates according to various study in EnDCR ranges from 70 to $95 \% .^{3,7,8}$ The overall results are significantly higher than with external DCR. ${ }^{9,10}$ The key to the improved success rates achieved with EnDCR is to attempt to replicate the external procedure as closely as possible. ${ }^{9,10}$ The creation of a large bony neo-ostium and mucosal flaps is the key to success. ${ }^{11,12}$

In order to achieve complete lacrimal sac exposure and correct sitting of the neo-ostium, the understanding of the nasal anatomy and its relationship to the lacrimal sac is vital. ${ }^{13,14}$ The upper half of the sac is behind the thick bone of the frontal recess of the maxilla and so the neo-ostium should be larger and higher than previously done. ${ }^{13,14} \mathrm{An}$ accurate understanding of the intranasal surgical anatomy is necessary for the success of the surgery. ${ }^{13,14}$

Full sac exposure requires extensive dissection of the frontal process of the maxilla either by using a powered drill or 3-mm punch forceps. ${ }^{15}$ The neo-ostium size and the mucosal preservation determines the ultimate success of the surgery. ${ }^{15}$ Nasal mucosa is preserved so that it can be fashioned to the lacrimal flaps created to achieve mucosal apposition of the marsupialized sac and of the nasal mucosa. $^{13,14}$ 
Silicon stents may lead to surgical failure by traumatic granulation tissue, punctual erosion or slitting of the canaliculi. ${ }^{4}$ In our study, we compared EnDCR done in 238 patients with 172 patients with only conventional EnDCR and the other with 66 patients with EnDCR and silicone tube stents.

\section{MATERIALS AND METHODS}

This is a comparative case series analysis study done in Department of ENT, Head and Neck Surgery and all the cases were operated by a single surgeon during the study period of 56 months between March 2007 and November 2011. A total of 238 patients having epiphora due to NLDO were included in the study. There were 136 females and 102 males in the study group and their age ranged from 8 to 68 years. The youngest was 8 years old boy and oldest was 68 years old female. The data collection and analysis was done by SPSS 17 program and a ethical committee clearance was taken (Table 1).

Detailed nasal and lacrimal apparatus examination with history and complaints were recorded. Coexistent nasal pathology, if present was explained to the patients. NLDO was confirmed by syringing where resistance to saline flow and regurgitation from opposite punctum seen. The patients were counseled for surgery with written informed consent. The patients in group B were explained about the stents to be introduced with photographs of earlier operated patients.

Routine blood and urine examination including detailed history, clinical features and duration were recorded. Diagnostic nasal endoscopy, X-ray paranasal air sinus was done in all cases. Contrast dacryocystography was done in 37 cases only and was not very helpful. Out of the 238 cases 172 patients operated without stents were analyzed under group A and the 66 patients who had silicon tube stents introduced were analyzed under group B.
Patients with common canaliculi blockage and failed cases of external DCR and EnDCR, revision EnDCR for all indications, patients with NLDO but having sinus diseases or other active nasal or systemic problems were excluded from the study. Acute dacryocystitis with abscesses were given a week of intravenous antibiotics and excluded from the study. The group A patients underwent EnDCR without stent and group B patients underwent EnDCR with silicon tube stent (Fig. 1). All the patients were operated under general anesthesia using wide angled $0^{\circ}$ and $45^{\circ}$ endoscopes (Fig. 2).

Under general anesthesia 1\% lidocaine $+1: 2,00,000$ adrenaline was infiltrated and mucosal flap was raised over the frontal process of maxilla. Bone was removed with Kerrison's straight and curved punches of 2 and $3 \mathrm{~mm}$, to the extent of approximately 1.0 to $1.5 \mathrm{~cm}$ and lacrimal sac was exposed. Medial wall of the sac was incised with sickle knife and the lumen of the sac exposed. The rim of the sac was opened into a microflap and marsupialized to the mucosa. Syringing was done using normal saline to confirm the patency of the neo-ostium made (Fig. 3). Silicon tube stent were used in group $B$ patients. The stent was passed through the lower punctum and pulled into the nose through the neoostium and later the other end was passed through the upper punctum and pulled out into the nose through the same neoostium and 3 to 4 knots were put in the nose (Fig. 4).

The nasal cavity was packed with ointment ribbon pack and removed after 24 hours. All the patients were discharged with oral antibiotics and anti inflammatory drugs with xylometazoline nasal drops and local antibiotic eye drops. Regular follow-up of patients was done at 1 to 2, 6 and 10 weeks and 6 months. Silicon stents were removed at 6th postoperative week. Subjective assessment for symptomatic improvement was done and objective assessment was done by syringing at 10th postoperative week and at 6th month follow-up.

Table 1: Patients profile

\begin{tabular}{lllll}
\hline \multirow{2}{*}{ Sex } & & Group A $(n=172)$ & Group B $(n=66)$ & $p$-value \\
& Male (102) & $79(77.42 \%)$ & $23(22.58 \%)$ & 0.12197 \\
Laterality & Female (136) & $93(68.38 \%)$ & $43(31.62 \%)$ & - \\
& Right & 77 & 35 & 0.25291 \\
& Left & 95 & 31 & - \\
\hline
\end{tabular}

Table 2: Intraoperative findings

\begin{tabular}{lll}
\hline Findings & $\begin{array}{l}\text { Group } A(n=172) \\
\text { Number of patients } \\
\text { and (Percentage) }\end{array}$ & $\begin{array}{l}\text { Group } B(n=66) \\
\text { Number of patients } \\
\text { and (Percentage) }\end{array}$ \\
\hline Mucoid discharge & $38(22.09)$ & $9(13.66)$ \\
Mucopurulent discharge & $69(40.11)$ & $32(48.48)$ \\
Purulent discharge & $13(7.55)$ & $7(10.66)$ \\
Hypertrophic lacrimal sac & $47(27.32)$ & $12(18.18)$ \\
Atrophic sac & $9(5.23)$ & $2(3.03)$ \\
\hline
\end{tabular}




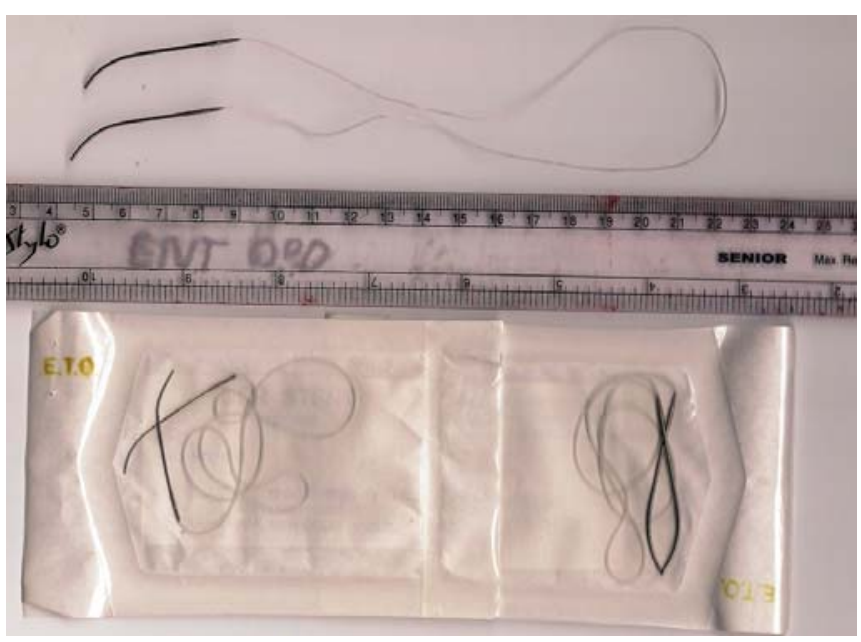

Fig. 1: Silicone tube stents thinner and thicker

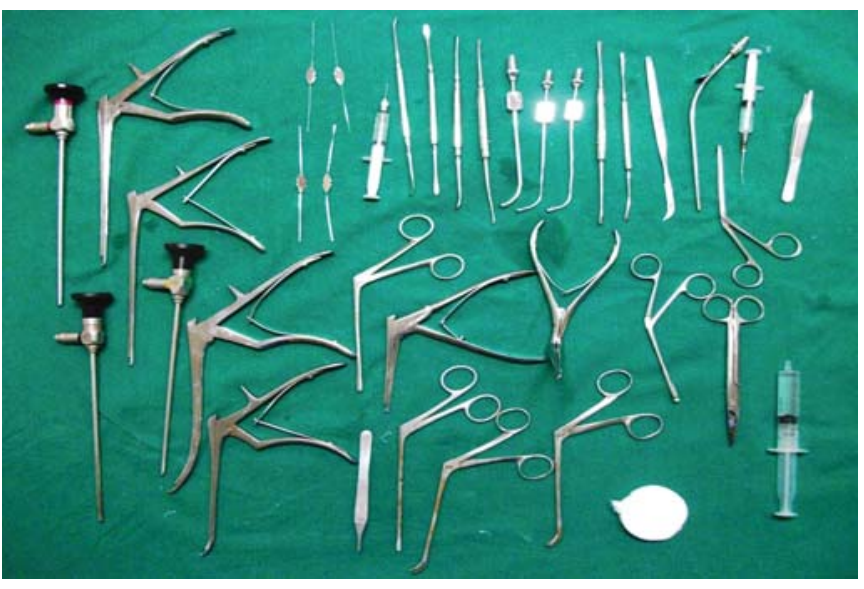

Fig. 2: Instruments used in EnDCR

\section{RESULTS}

The findings in both the groups were analyzed. The commonest presenting symptom was epiphora, being present in all 238 patients. Mucoid to mucopurulent discharge was seen in all the patients on pressing the sac externally. The mean duration of symptoms was found to be 5 to 30 months. All cases were operated under general anesthesia and were uneventful in both the groups. The mean age in group A was 42 years and in group B was 44 years.

Intraoperatively on incising the sac mucoid discharge was seen in $19.74 \%$ of cases, mucopurulent in $42.43 \%$ of cases and purulent in $78.4 \%$ of cases. The sac was thickened and hypertrophic in $24.78 \%$ and atrophic in $4.62 \%$ of cases

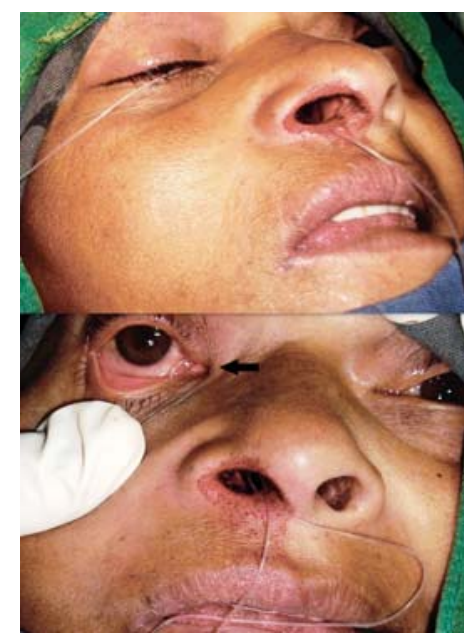

Fig. 3: Silicon tube stent being introduced intraoperatively

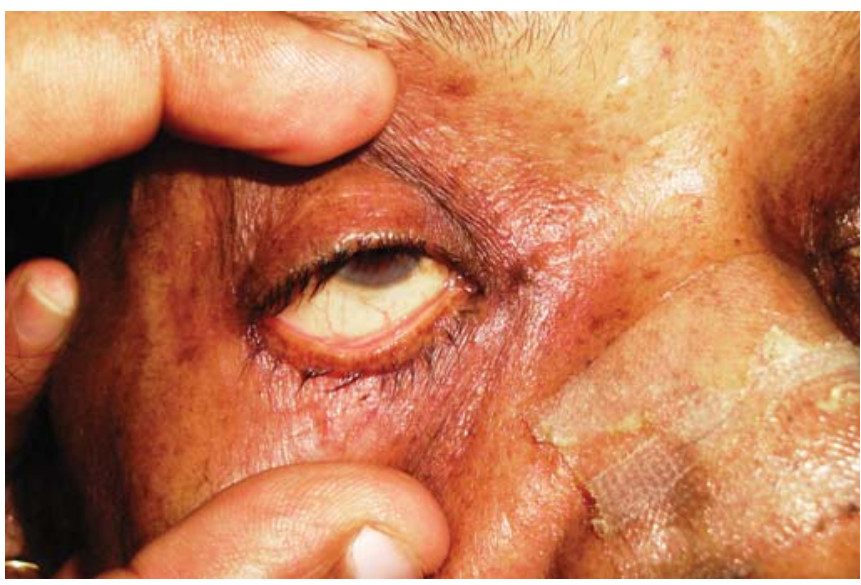

Fig. 4: Silicon tube stent in place in a old woman

(Tables 2 and 3). All patients were subjected to diagnostic nasal endoscopy of the neo-ostium on follow-up. The neoostium was inspected by syringing at 1, 2, 6 and 10 weeks and 6 months. Subjective evaluation was made in terms of complete, partial or no relief from symptoms (Table 4). Objective evaluation was done by syringing. Syringing was performed in group B at 6 and 10 weeks and 6 months after removal of stents and in group A at 1, 2, 6 and 10 weeks and 6 months.

Syringing was termed patent when there was no resistance to the flow of the fluid through sac to nasopharynx. It was termed partially patent when some of the fluid regurgitated through the upper punctum and some

Table 3: Intraoperative findings

\begin{tabular}{|c|c|c|c|c|c|c|c|c|c|c|}
\hline & \multicolumn{5}{|c|}{$\begin{array}{l}\text { Symptomatic relief } \\
\text { group } A(n=172)\end{array}$} & \multicolumn{5}{|c|}{$\begin{array}{l}\text { Symptomatic relief } \\
\text { group } B(n=66)\end{array}$} \\
\hline & $1 w k$ & $2 w k s$ & $6 w k s$ & 10 wks & $6 \mathrm{mo}$ & $1 w k$ & $2 w k s$ & $6 w k s$ & $10 w k s$ & $6 \mathrm{mo}$ \\
\hline Patients with complete relief & 151 & 151 & 158 & 158 & 157 & 59 & 59 & 61 & 61 & 60 \\
\hline Patients with partial relief & 21 & 21 & 14 & 9 & 4 & 7 & 7 & 5 & 4 & 4 \\
\hline Patients with no relief & 0 & 0 & 0 & 5 & 11 & 0 & 0 & 0 & 1 & 2 \\
\hline
\end{tabular}




\begin{tabular}{|c|c|c|c|c|c|c|c|c|c|c|}
\hline & \multicolumn{5}{|c|}{ Group A $(n=172)$} & \multicolumn{5}{|c|}{ Group B $(n=66)$} \\
\hline & $1 w k$ & $2 w k s$ & $6 w k s$ & $10 w k s$ & $6 \mathrm{mo}$ & $1 w k$ & $2 w k s$ & $6 w k s$ & $10 w k s$ & $6 \mathrm{mo}$ \\
\hline Patients with syringing patent & 172 & 170 & 158 & 156 & 154 & - & - & 66 & 62 & 59 \\
\hline Patients with partially patent & 0 & 2 & 11 & 7 & 5 & - & - & 0 & 2 & 1 \\
\hline Patients with syringing blocked & 0 & 0 & 3 & 9 & 13 & - & - & 0 & 2 & 6 \\
\hline
\end{tabular}

Table 5: Complications

\begin{tabular}{lcccc}
\hline \multirow{2}{*}{ Findings } & \multicolumn{2}{c}{ Group A $(n=172)$} & & \multicolumn{2}{c}{ Group B (n=66) } \\
\cline { 2 - 3 } & No. of patients & $\%$ & No. of patients & 2 \\
\hline Postoperate bleeding (minor) & 3 & 1.74 & 0 & 3.03 \\
Difficulty in removal of stent & 0 & 0 & 0 & 0 \\
Spontaneous expulsion of stent & 0 & 0 & 0 & 0 \\
Closure of rhinostomy opening & 0 & 0 & 5 & 7.57 \\
Corneal irritation due to stent & 0 & 0 & 3 & 4.54 \\
Patient asked early removal of stent & 0 & & 0 \\
\hline
\end{tabular}

Table 6: Endoscopic findings of objective evaluation

\begin{tabular}{lllll}
\hline \multicolumn{1}{c}{$\begin{array}{c}\text { Findings } \\
\text { (DNE on 6th month) }\end{array}$} & & $\begin{array}{l}\text { Group } A(n=172) \\
\text { No. of patients and \% }\end{array}$ & $\begin{array}{l}\text { Group B }(n=66) \\
\text { No. of patients and \% }\end{array}$ & $p$-value \\
\hline Neo-ostium visible & Patent & $162(94.18 \%)$ & $61(92.42 \%)$ & 0.61658 \\
& Stenosed & $10(5.82 \%)$ & $5(7.58 \%)$ & - \\
Granulation at rhinostome site & Present & $13(7.55 \%)$ & $4(6.06 \%)$ & 0.68799 \\
& Absent & $159(92.45 \%)$ & $62(93.94 \%)$ & - \\
Nasal synechiae & & $23(13.37 \%)$ & $11(16.66 \%)$ & 0.51554 \\
& & $149(86.63 \%)$ & $55(83.34 \%)$ & - \\
Syringing patency present & & $154(89.53 \%)$ & $59(89.39 \%)$ & 0.97467 \\
\hline
\end{tabular}

passed into nasopharynx. It was termed blocked when whole of the fluid regurgitated through the upper punctum and no fluid passed into the nasopharynx (Table 5). Difficulty in removal of stent was not seen in any of the 66 patients with stents and none of them had spontaneous expulsion. Corneal irritation due to the stents were seen five patients in group B (7.57\%). No major intraoperative and postoperative complications were seen in the study (Table 6).

In our study at 6 months of follow-up, 89.53\% success in syringing patency was seen in group A and 89.39\% success in syringing patency was seen in group B. Pearson's Chi-square test was applied to test the significance of difference between the success rates in groups A and B. No significant difference in success rates were seen in groups A and B (Graph 1). Septoplasty was done in 33 cases in group $A$ and 7 cases in group $B$, while 11 synechiolysis in group $\mathrm{A}$ and 4 in group $\mathrm{B}$ to expose the frontal process of maxilla (Graph 2).

\section{DISCUSSION}

EnDCR is indicated for congenital and acquired nasolacrimal duct obstruction (NLDO). ${ }^{16}$ It is the most

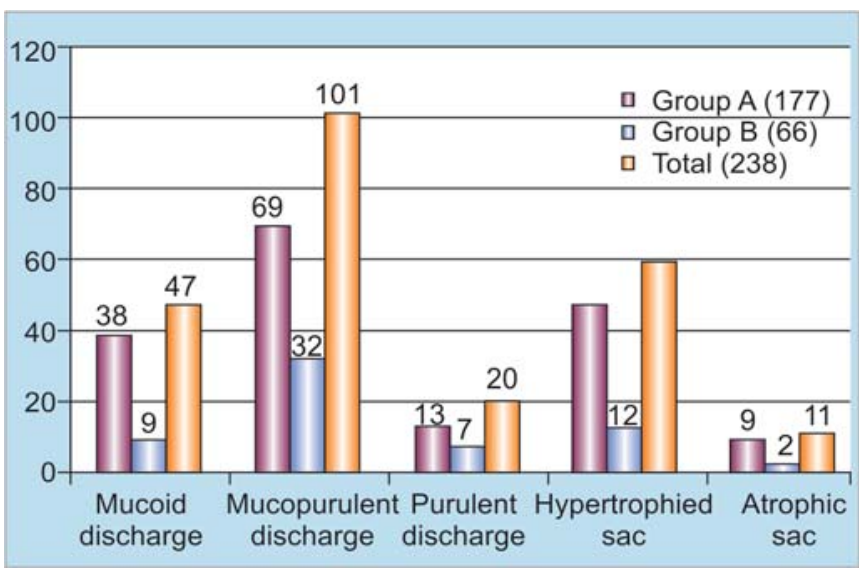

Graph 1: Intraoperative findings

common open surgical procedure carried out for nasolacrimal drainage system obstruction. ${ }^{16}$ It has a high success rate with limited follow-up and is also costeffective. ${ }^{16}$ Epiphora is a disturbing situation, which is a continuous tearing of the eyes due to NLDO. ${ }^{17}$ This situation not only causes recurrent infections but also disturbs the patient cosmetically. ${ }^{17}$ The main purpose of the treatment is to eliminate the obstruction and to accomplish normal tear flow. ${ }^{17}$ 


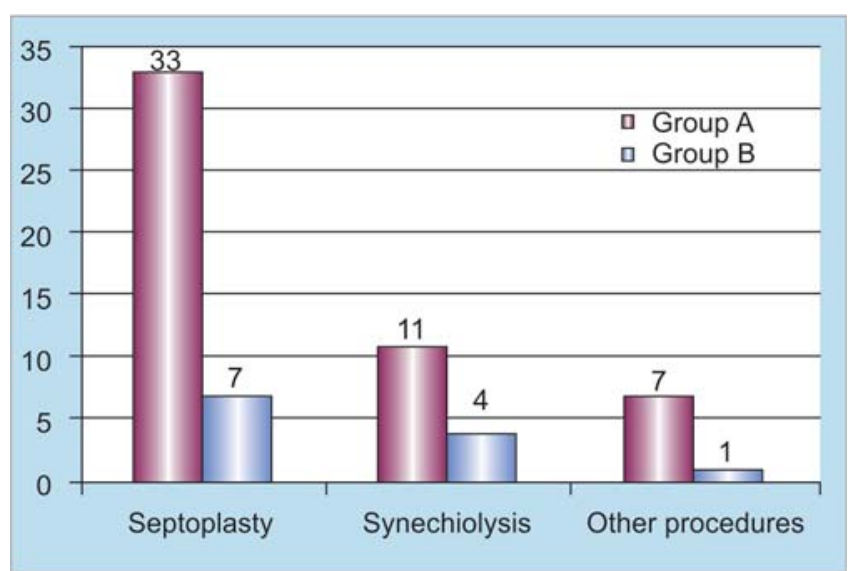

Graph 2: Other procedures done along with EnDCR during surgery

Chronic dacryocystitis is more common in women of low socioeconomic group due to their bad personal habits, long duration of exposure to smoke in kitchen and dust in the external environment. ${ }^{18}$ Other possible causes are congenital and anatomical narrowing of nasolacrimal drainage system in females as compared to males. ${ }^{18}$ Congenital NLDO is estimated to occur in 6 to $20 \%$ of new born infants. ${ }^{19}$ Among them 80 to $96 \%$ resolves spontaneously in the first year and rest in the second year. ${ }^{19}$

EnDCR is a commonly performed operation in which a fistulous tract is created between the lacrimal sac and the nasal cavity in order to relieve the epiphora due to nasolacrimal duct obstruction. ${ }^{18}$ EnDCR can be performed in acute dacryocystitis, pyocele and in atrophic rhinitis where external DCR is contraindicated. ${ }^{18} \mathrm{~A}$ wide intranasal stomas as well as adequate removal of bone around the stoma are needed to reduce the chances of postoperative stenosis and adhesions resulting in good success rate. ${ }^{20}$ Inadequate removal of bone is the commonest cause of postoperative stomal stenosis. ${ }^{20}$ The use of powered instruments and lasers are known to cause increased granulations resulting in fibrosis and scarring. ${ }^{21}$ Silicon tube stent maintains the patency of fistula during postoperative healing period. ${ }^{1}$

The size of the bony ostium and the extent of the sac exposure are important factors in determining postoperative patency of the newly created ostium. ${ }^{9-11,15}$ Approximately two-third of the lacrimal sac is above the axilla of the middle turbinate which means, in order to accomplish complete sac exposure, a large amount of thick bone over the axilla of the middle turbinate and the lateral wall of the agar nasi has to be removed. ${ }^{11}$

Removal of this thick bone is best achieved with a $3 \mathrm{~mm}$ bone punch as it allows meticulous bone removal without damaging the sac lining and other nasal structures. ${ }^{11}$ The common canaliculus should be identified as a landmark for adequate sac exposure once the lacrimal sac is opened, because at least two-thirds of the sac is below this opening. ${ }^{11}$ Once the lacrimal sac has been opened it is important to achieve primary intention healing between the edges of the sac and the nasal mucosa. ${ }^{11}$ The U-shaped flap fashioned at the end of the procedure allows for primary intention healing to occur. ${ }^{11}$

In the posterosuperior region of the lacrimal sac, apposition with the nasal mucosa is difficult so the exposed agar nasi cell mucosa is routinely opened and apposition between this mucosa and the lacrimal mucosa is achieved in this area. ${ }^{15}$ This flap can be stabilized by positioning two small cut stripes of merogel or sharp ribbon guaze along the posterior and inferior edges of the junction between the sac and nasal wall. ${ }^{11}$ This apposition of sac mucosa to nasal mucosa is similar to what is achieved in external DCR by suturing of the anterior and posterior sac flaps to the nasal mucosa. ${ }^{11}$

Silicon tube stents were used in 66 patients at the end of the procedure. In 172 patients, no stents were used because a wide neo-ostium was punched out, full lacrimal sac exposed and marsupilation of the entire sac with the lateral wall done. The bony surfaces were covered with mucosal flaps and marsupialized sac with no bone exposed leading for a healing by primary intention. ${ }^{11}$

Harvinder et al in their 24 cases series have shown that EnDCR with wide neo-ostium, and primary healing with mucosal flaps and without stents documented $91.66 \%$ success which was comparable to results with stents and far better than external DCR. ${ }^{3,7,8}$ Apart from stomal stenosis other reported complications of EnDCR include hemorrhage, breach of lamina papyracea, herniation of orbital fat and orbital hemorrhage. ${ }^{22}$ It is also reported that by avoiding dilatation and probing of the punctum the chances of granuloma formation and punctual stenosis is reduced. ${ }^{12}$ Also ecchymosis around the canthal area, minor cheek hematoma and increased operative time is avoided. ${ }^{23}$ EnDCR gives very good functional results as the pumping action of the orbicularis oculi muscle is intact and a good knowledge of the anatomy of the lateral nasal wall is essential $^{24}$ (Graph 3).

Sharma found a success rate of $88.5 \%$ in his 165 patients study with silicon tube stents. ${ }^{25}$ Kakkar reported 85 to $90 \%$ success with stent and nearly the same success without silicon stents. ${ }^{1}$ Jin reported primary success rate of $83 \%$ with EnDCR with stent and in $17 \%$ cases rhinostomy opening was found to be obstructed by granulation or synechiae. ${ }^{25}$ Sprekelson reported success with EnDCR with stent in $85 \%$ patients. ${ }^{7}$ Unlu et al reported $85.7 \%$ success rate in patients with use of silicon stents and $87.5 \%$ in patients without stents. ${ }^{26}$ Durvasula has reported good 


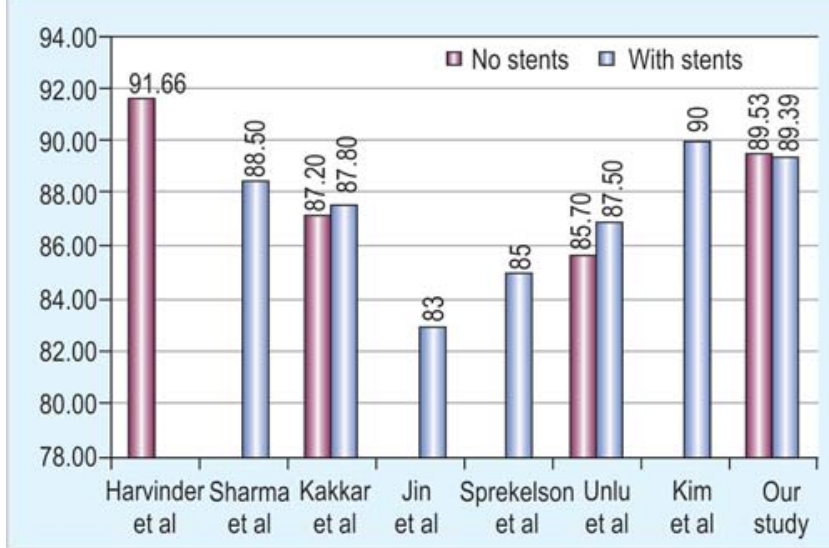

Graph 3: Comparison of success rates

results with use of stents after 3 months. ${ }^{5}$ Zilelioglu reported lacerations of puncta due to probing and bicanalicular silicon intubation. ${ }^{27} \mathrm{Kim}$ et al reported decreased long-term patency with stents with a success rates dropping from 90 to $77 \%{ }^{28}$ Also a major factor negatively affecting patency after stent removal was contraction of the lacrimal sac at the time of stent removal. ${ }^{28}$

The success rate of EnDCR without stent reported in the literature varies from 90 to $96 \%$ which is comparable to our study. Also a varied success rate of 85 to $95 \%$ with silicon stenting is reported in literature which is also comparable to the results in our study.

\section{CONCLUSION}

The surgical success rate of EnDCR with silicon tube stent is nearly equal to the patients without stent in our study. Minimal patient discomfort and complications are seen with silicon tube stents. As success rates of EnDCR are not significantly less compared to that with stents, routine use of stents is not advocated. So stenting, probing and dilatation are not advocated routinely in all cases and a wide neoostium with mucosal flaps and primary healing is the secret to success in EnDCR.

\section{REFERENCES}

1. Kakkar V, Chugh JP, Sachdeva S, Sharma N, Ramesh. Endoscopic dacryocystorhinostomy with and without silicone stent: A comparative study. Int J Otorhinolaryng 2009;9(1).

2. Benger R, Forer M. Endonasal dacryocystorhinostomy: Primary and secondary. Aust NZJ Ophthalmol 1993;21(3):441-42.

3. Metson R. The endoscopic approach for revision dacryocystorhinostomy. Laryngoscope 1990;100(12):1344-47.

4. Tripathi A, Lesser J, O Donnel NP. Local anaesthetic EnDCR: Analysis of patient acceptability and various factors affecting the success of the procedure. Eye 2002;16:146-49.

5. Durvasula VSP,Gatland DJ. Endoscopic dacryocystorhinostomy: Long-term techniques and evolution of surgical techniques. J Laryngol Otol 2004;118:628-32.
6. Hehar SS, Jones NS, Sadiq A, Downes RN. Endoscopic holmium: YAG Laser dacryocystorhinostomy is safe and effective as a day care procedure. J Laryngol Otol 1997;111: 1056-59.

7. Sprekelson MB. Endoscopic dacryocystorhinostomy—surgical techniques and results. Laryngoscope 1996;106:187-89.

8. Weidenbecher M, Hosemann W, Buhr W. Endoscopic endonasal dacryocystorhinostomy: Results in 56 patients. Ann Otol Rhinol Laryngol 1994;103:363-67.

9. Weiham RA. Management of unsuccessful lacrimal surgery. Br J Ophthalmology 1987;71:152-57.

10. Hartikainen J, Grenman R, Puukka P, Seppa H. Prospective randomized comparison of external dacryocystorhinostomy and endonasal laser dacryocystorhinostomy. Ophthalmology 1998;105:1106-13.

11. Wormald PJ. Powered endonasal dacryocystorhinostomy. Laryngoscope 2002;112:69-71.

12. Tsirbas A, Wormald PJ. Mechanical endonasal DCR with mucosal flaps. Am J Ophthalmol 2003;135(1):79-86.

13. Duffy MT. Advances in lacrimal surgery. Curr Opin Ophthalmol 2000;11:352-56.

14. Wormald PJ, Kew J, van Hasselt CA. The intranasal anatomy of the nasolacrimal sac in endoscopic dacryocystorhinostomy. Otolaryngol Head Neck Surg 2000;123:307-10.

15. Mann BS, Wormald PJ. Endoscopic assessment of the dacryocystorhinostomy ostium after endoscopic surgery. Laryngoscope 2006;116:1172-74.

16. McDonogh M, Meiring JH. Endoscopic transnasal dacryocystorhinostomy. J Laryngol Otol 1989;103(6):585-87.

17. Ozgur Y, Samancioglu M, Taskin U, Ceylan S, Elutar K, Yener M. External and endoscopic dacryocystorhinostomy in chronic dacryocystitis: comparison of results. Eurv Arch Otorhinolaryngol 2007;264:879-85.

18. Singh M, Jain V, Gupta SC, Singh SP. Intranasal endoscopic DCR in cases of dacryocystitis. Ind Jour of Otolaryn, Head Neck Surgery 2004;56(3).

19. Leibawittch I, Selva D, Tsirbas A, Greenrod E, Peter J. Pediatric endoscopic endonasal cacryocystorhonostomy in congenital nasolacrimal obstruction: Grafes Arch Clin Ophthalmol 2006; 244:1250-54

20. Yung MW, Hardman Lea S. Enoscopic interior dacryocystorhinostomy: Clin Otolaryngol 1998;23:152-57.

21. Whittet HB, Shun S, Awdry P. Functional endoscopic transnasal dacryocystorhinostomy: Eye 1993;7:545-49.

22. Wormald PJ, Tsibas A. investigations and endoscopic treatment for functional and anatomic obstruction of NLD system. Clin Otolaryngol Allied Sci 2004;29(4):352-56.

23. Gupta AK, Rijuneeta. External dacryocystorhinostomy without probing: Surgical outcome: Clinical Rhinology: An International Journal 2010;3(2):77-80.

24. Javate R, Pamintuan F. Endoscopic radiofrequency assisted DCR with double stent: A personal experience: Orbit 2005:24(1): $15-22$.

25. Sharma BR. Nonendoscopic endonasal dacryocystorhinostomy versus external dacryocystorhinostomy. Kathmandu Univ Med J 2008;6(4):Issue 24, 437-42.

26. Unlu HH, Toprak B. Comparison of surgical outcomes in primary endoscopic dacryocystorhinostomy: With or without silicon intubation. Ann Otol Rhinol Laryngol 2002;111(8): 704-09.

27. Zilelioglu G, Tekeli O, Ugurba SH. Results of endoscopic endonasal non-laser dacryocystorhinostomy. Doc Ophthalmol 2002;105(1):57-62. 
28. Kim JH, Shin JH, Song HY, et al. Long-term results and factors affecting patency after removal of nasolacrimal stents. J Vasc Interv Radiol 2006;17(7):1125-30.

\section{ABOUT THE AUTHORS}

\section{Sudhir M Naik (Corresponding Author)}

Associate Professor, Department of ENT and Head and Neck Surgery KVG Medical College and Hospital, Kurunjibag, Sullia, Karnataka India, Phone: 919916807109, e-mail: sud223@gmail.com

\section{Annapurna S Mushannavar}

Senior Resident, Department of ENT and Head and Neck Surgery KVG Medical College and Hospital, Kurunjibag, Sullia, Karnataka, India

\section{S Ravishankara}

Associate Professor, Department of ENT and Head and Neck Surgery KVG Medical College and Hospital, Kurunjibag, Sullia, Karnataka, India

\section{Mohan K Appaji}

Professor and Head, Department of ENT and Head and Neck Surgery KVG Medical College and Hospital, Kurunjibag, Sullia, Karnataka India

\section{MK Goutham}

Senior Resident, Department of ENT and Head and Neck Surgery KVG Medical College and Hospital, Kurunjibag, Sullia, Karnataka India

\section{Nonthombam Pinky Devi}

Senior Resident, Department of ENT and Head and Neck Surgery KVG Medical College and Hospital, Kurunjibag, Sullia, Karnataka, India

\section{Sarika S Naik}

Senior Resident, Department of Anesthesia and Critical Care Narayana Hrudayalaya, Bengaluru, Karnataka, India 